\title{
Machine learning-based ability to classify psychosis and early stages of disease through parenting and attachment-related variables is associated with social cognition
}

\author{
Linda A. Antonucci ${ }^{1,2^{*}} \oplus$, Alessandra Raio², Giulio Pergola ${ }^{2,3}$, Barbara Gelao², Marco Papalino², \\ Antonio Rampino², Ileana Andriola ${ }^{4}$, Giuseppe Blasi² and Alessandro Bertolino²
}

\begin{abstract}
Background: Recent views posited that negative parenting and attachment insecurity can be considered as general environmental factors of vulnerability for psychosis, specifically for individuals diagnosed with psychosis (PSY). Furthermore, evidence highlighted a tight relationship between attachment style and social cognition abilities, a key PSY behavioral phenotype. The aim of this study is to generate a machine learning algorithm based on the perceived quality of parenting and attachment style-related features to discriminate between PSY and healthy controls (HC) and to investigate its ability to track PSY early stages and risk conditions, as well as its association with social cognition performance.

Methods: Perceived maternal and paternal parenting, as well as attachment anxiety and avoidance scores, were trained to separate 71 HC from 34 PSY (20 individuals diagnosed with schizophrenia + 14 diagnosed with bipolar disorder with psychotic manifestations) using support vector classification and repeated nested cross-validation. We then validated this model on independent datasets including individuals at the early stages of disease (ESD, i.e. first episode of psychosis or depression, or at-risk mental state for psychosis) and with familial high risk for PSY (FHR, i.e. having a first-degree relative suffering from psychosis). Then, we performed factorial analyses to test the group x classification rate interaction on emotion perception, social inference and managing of emotions abilities.

Results: The perceived parenting and attachment-based machine learning model discriminated PSY from HC with a Balanced Accuracy (BAC) of 72.2\%. Slightly lower classification performance was measured in the ESD sample (HC-ESD $B A C=63.5 \%)$, while the model could not discriminate between FHR and $\mathrm{HC}(\mathrm{BAC}=44.2 \%)$. We observed a significant group $x$ classification interaction in PSY and HC from the discovery sample on emotion perception and on the ability to manage emotions (both $p=0.02$ ). The interaction on managing of emotion abilities was replicated in the ESD and $\mathrm{HC}$ validation sample $(p=0.03)$.
\end{abstract}

Conclusion: Our results suggest that parenting and attachment-related variables bear significant classification power when applied to both PSY and its early stages and are associated with variability in emotion processing. These

\footnotetext{
${ }^{*}$ Correspondence: lindaaantonucci@gmail.com

${ }^{1}$ Department of Education, Psychology, Communication, University

of Bari Aldo Moro, Via Scipione Crisanzio 42, 70122 Bari, Italy

Full list of author information is available at the end of the article
} original author(s) and the source, provide a link to the Creative Commons licence, and indicate if changes were made. The images or other third party material in this article are included in the article's Creative Commons licence, unless indicated otherwise in a credit line to the material. If material is not included in the article's Creative Commons licence and your intended use is not permitted by statutory regulation or exceeds the permitted use, you will need to obtain permission directly from the copyright holder. To view a copy of this licence, visit http://creativecommons.org/licenses/by/4.0/. The Creative Commons Public Domain Dedication waiver (http://creativeco mmons.org/publicdomain/zero/1.0/) applies to the data made available in this article, unless otherwise stated in a credit line to the data. 
variables could therefore be useful in psychosis early recognition programs aimed at softening the psychosis-associated disability.

Keywords: Parental care, Parental overprotection, Adult attachment style, Machine learning, Schizophrenia, Bipolar disorder, Risk for psychosis

\section{Background}

Schizophrenia and bipolar disorder with psychotic manifestations are two devastating psychosis-spectrum disorders that dramatically affect individuals' quality of life and personal functioning [1]. Indeed, they are strongly associated with lifetime disability [2], reduced life expectancy [3], and increased relative risk of suicide [4]. Furthermore, they are both characterized by strong and largely overlapping anomalies in neurocognition and social cognition $[5,6]$, as well as by thought disturbances [7]. Given this evidence and the strong and long-lasting disability affecting individuals with psychosis (PSY), especially individuals suffering from schizophrenia or from bipolar disorder with psychotic manifestations, the identification of markers of disease to be targeted in early identification or prevention strategies aimed at softening the PSY-associated burden is becoming more and more crucial in the clinical psychology and personalized medicine fields.

In the pathophysiology of psychosis, environmental factors play a crucial role [8]. Amongst those, early adverse experiences that occurred in childhood, especially those related to psychological or physical abuse, are highly prevalent in individuals diagnosed with psychosis (PSY) [9]. Notably, childhood traumatic experiences are associated with more severe clinical profiles and higher functional impairments already in the early stages and risk conditions of mental illness [10]. According to previous literature, adverse childhood experiences are strongly associated with perceived negative parenting, which is in turn associated with attachment insecurity $[11,12]$. Specifically, according to attachment theory [13], an innate motivational system prompts individuals to proximity seeking to alleviate distress. The quality of these experiences of proximity with significant others leads to the generation of individual cognitive-affective representations (i.e. "internal working models") of self and others [14]. These models are key to affect regulation throughout the lifespan, as they guide how information from the social world is appraised, thus in turn potentially affecting social cognition abilities [15]. In adulthood, a secure attachment style, often originating from positive parenting experiences [12], is indeed associated with high distress tolerance and positive affect regulation [16]. On the other hand, interacting with unpredictable or insensitive attachment figures may make the development of a stable and secure mental foundation more difficult [17-19] and lead to attachment insecurity, declined either through attachment anxiety (e.g., individuals are strongly vigilant to social threats and rejection experiences, and tend to overestimate the impact of negative emotions), or through attachment avoidance (e.g., individuals disavow the need of being comforted by others, avoid closeness and intimacy, tend to suppress the impact of emotions) [20]. Given its association with affect regulation, it is not surprising that studies have consistently reported a significant association between attachment insecurity and social cognition impairments, a key characteristic of PSY [21, 22]. Furthermore, both negative parenting and attachment insecurity have been associated with reduced coping strategies and increased likelihood of emotional breakdowns [17]. In this framework, low parenting abilities, as well as attachment insecurity, have been previously considered as general environmental factors of vulnerability for mental illness [16] whose effects are amplified by other genetic and/or environmental factors $[8,23]$ within the psychosis risk pathways.

This evidence, therefore, suggests that both perceived parenting and attachment style may have value as potential targets of psychosis in early recognition strategies. Indeed, several univariate studies have reported significant associations between attachment insecurity and clinically relevant aspects of psychosis, e.g. negative symptoms [24], paranoia [25], negative beliefs [26-28], and social withdrawal [29]. However, univariate studies have characterized main effects or interactions between attachment security and psychosis only at the group-level, thus lacking in generalizability potential and underestimating inter-individual heterogeneity [30, 31]. Furthermore, little is known about the association of perceived negative parenting and attachment insecurity with earlier stages of psychosis, as well as with its risk conditions (i.e., clinical, familial). Thus, the extent of potential of parenting and attachment factors to be targeted in early intervention programs is still unclear. A strategy to circumvent these shortcomings is to employ machine learning techniques. Indeed, machine learning allows quantifying sensitivity, specificity and generalizability of a given set of variables at the single-subject level [32, 33], rather than just characterizing group differences. Therefore, employing machine learning to deeply investigate the discriminative power of parenting and 
attachment-related variables in both psychosis and early stages of disease would lead to a better understanding of how negative parenting and attachment insecurity might be considered core vulnerability factors of psychosis and its early stages. From a clinical perspective, this better understanding would potentially allow better tailoring of environmental factors within early identification programs. Specifically, accurate and generalizable machine learning models could potentially lead to the implementation of refined and individualized preventative interventions, and/or mental health promotion programs, which would in turn have a greater impact in the reduction of the burden associated with psychosis in terms of symptoms, quality of life, management [30].

Thus, the aim of this study is threefold: (i) to generate a parenting and attachment-based machine learning model which correctly discriminates between PSY and healthy controls (HC); (ii) to test whether this model could track the early stages of psychosis and/or risk conditions in independent samples; (iii) to investigate in both psychosis and its early stages the potential association between model's performance and social cognition impairments. We hypothesized that both perceived parenting and attachment-related variables will bear significant PSY vs. $\mathrm{HC}$ classification performance. Furthermore, we hypothesized that this model will generalize to early stages of psychosis and familial risk conditions. Moreover, we expected that the discriminative ability of the model will be associated with social cognition abilities.

\section{Methods}

\section{Sample determination}

A total of 234 individuals, all Caucasians native of the Apulia region, Italy, participated in the study. Inclusion and exclusion criteria are reported in Supplementary Information, section "Background". The discovery sample was composed of 105 individuals, of which $71 \mathrm{HC}$ and 34 PSY on stable antipsychotic treatment for at least one month (Table 1A). Of the PSY, 20 were diagnosed with schizophrenia and 14 with bipolar disorder with psychotic symptoms according to the Structural Clinical Interview for DSM IV-TR [34]. Moreover, 90 individuals were included in the validation clinical sample (Table 1B). Of those, 60 were $\mathrm{HC}$ and 30 were individual at the early stages of disease (ESD) compared with PSY. Specifically, 9 were labeled as First Episode of Depression, 9 as First Episode of Psychosis, and 12 as At-Risk Mental State for psychosis. A detailed description of the clinical characteristics of the ESD group is reported in Supplementary Information, section "Background". Furthermore, 26 HC and 13 individuals with a Familial High Risk for psychosis (FHR, i.e., with no DSM IV Axis I diagnosis, but with a first-degree relative affected either by schizophrenia or by bipolar disorder-Table $1 \mathrm{C}$ ) were included in the validation familial risk sample. Both familial risk and clinical validation samples were used for replication purposes (section "Out-of-sample validation analyses"). ANOVA and $x^{2}$ were used to test for group differences in terms of demographics both within- and between- samples (Table 1).

\section{Perceived parental bonding and adult attachment assessment}

All participants completed the Parental Bonding Instrument (PBI) for the assessment of the perceived parental bonding [35] (Supplementary Information, section "Methods"). The PBI is a 25 -items self-report questionnaire investigating two main dimensions, "care" and "overprotection", separately for maternal bonding and paternal bonding. The "care" dimension reflects perceived parental warmth, affection, and involvement in contrast to coldness, indifference, and rejection. On the other hand, the "overprotection" dimension reflects perceived parental psychological control and intrusion in contrast to the encouragement of autonomy and independence. The Italian version of the PBI shows good psychometric properties [36]. In this study, we focused on PBI continuous scores of separate maternal and paternal care and overprotection (4 variables in total) for analysis purposes.

To assess the adult attachment style, all individuals underwent the 36-items self-report questionnaire Experiences in Close Relationships Scale (ECR) [37]. The ECR allows researchers to investigate feelings and behaviors related to significant relationships in adulthood along two dimensions: "anxiety about abandonment" and "avoidance of closeness". The anxiety factor includes intense concerns for romantic relationships, fear of being abandoned and frequent requests to greater involvement of partners; the second factor, avoidance, includes difficult and uncomfortable feelings in managing emotions and in relying on partners. The Italian version of the ECR shows good psychometric properties [38]. In this study, we focused on continuous scores of ECR anxiety and avoidance for analysis purposes.

Two-sample t-tests were employed to assess differences in discovery and validation samples for each of the PBI and ECR variables of interest (Table 2). All significant $p$ values were $<0.05$.

\section{Social cognition assessment}

All individuals were administered three tests, each aimed at investigating a different aspect of socio-cognitive abilities: 
Table 1 Demographic, clinical and neuropsychological characteristics of: (A) discovery sample; (B) validation clinical sample; (C) validation familial risk sampl

$\begin{array}{llll}\text { All subjects }(\text { mean } \pm \text { SD) } & \text { HC } & \text { PSY } & \text { HS. PSY }\end{array}$

$($ mean $\pm S D) \quad$ (mean $\pm S D) \quad$ p value

\begin{tabular}{|c|c|c|c|c|}
\hline \multicolumn{5}{|l|}{ A. Discovery sample } \\
\hline N & 105 & 71 & 34 & n.a \\
\hline Gender Ratio (M/F) & $58 / 47$ & $35 / 36$ & $23 / 11$ & 0.119 \\
\hline Age & $31.96 \pm 10.14$ & $28.82 \pm 6.43$ & $38.53 \pm 13.05$ & $<0.001^{*}$ \\
\hline Socio-economic Status & $40.58 \pm 17.01$ & $40.77 \pm 17.61$ & $40.18 \pm 15.94$ & 0.867 \\
\hline WAIS IQ & $105.77 \pm 15.97$ & $111.04 \pm 10.93$ & $94.76 \pm 19.13$ & $<0.001^{*}$ \\
\hline Premorbid IQ & $114.27 \pm 5.62$ & $116.40 \pm 2.69$ & $109.80 \pm 7.33$ & $<0.001^{*}$ \\
\hline GAF total score & $51.79 \pm 15.72$ & n.a & $51.79 \pm 15.72$ & n.a \\
\hline \multirow[t]{2}{*}{ Chlorpromazine eq } & $174.60 \pm 110.13$ & n.a & $174.60 \pm 110.13$ & n.a \\
\hline & All subjects (mean $\pm \mathrm{SD}$ ) & $\begin{array}{l}\mathrm{HC} \\
(\text { mean } \pm \mathrm{SD})\end{array}$ & $\begin{array}{l}\text { ESD } \\
(\text { mean } \pm S D)\end{array}$ & $\begin{array}{l}\mathrm{HC} \text { vs. ESD } \\
\text { p value }\end{array}$ \\
\hline \multicolumn{5}{|c|}{ B. Validation clinical sample } \\
\hline $\mathrm{N}$ & 90 & 60 & 30 & n.a \\
\hline Gender ratio (M/F) & $35 / 55$ & $17 / 43$ & $18 / 12$ & $0.007^{*}$ \\
\hline Age & $23.04 \pm 6.33$ & $22.95 \pm 6.27$ & $23.23 \pm 6.56$ & 0.843 \\
\hline Socio-Economic Status & $42.62 \pm 14.50$ & $43.81 \pm 14.78$ & $40.25 \pm 13.87$ & 0.275 \\
\hline WAIS IQ & $105.41 \pm 11.26$ & $106.60 \pm 10.44$ & $103.03 \pm 12.61$ & 0.158 \\
\hline Premorbid IQ & $114.28 \pm 3.55$ & $115.33 \pm 2.49$ & $112.19 \pm 4.39$ & 0.300 \\
\hline GAF total score & $64.04 \pm 15.03$ & n.a & $64.22 \pm 15.34$ & n.a \\
\hline \multirow[t]{2}{*}{ Chlorpromazine eq } & $91.67 \pm 46.87$ & n.a & $95.45 \pm 47.19$ & n.a \\
\hline & All subjects (mean $\pm S D$ ) & $\begin{array}{l}\mathrm{HC} \\
(\text { mean } \pm \mathrm{SD})\end{array}$ & $\begin{array}{l}\text { FHR } \\
\text { (mean } \pm S D)\end{array}$ & $\begin{array}{l}\mathrm{HC} \text { vs. FHR } \\
p \text { value }\end{array}$ \\
\hline \multicolumn{5}{|c|}{ C. Validation familial risk sample } \\
\hline N & 39 & 26 & 13 & n.a \\
\hline Gender Ratio (M/F) & $15 / 24$ & $10 / 16$ & $5 / 8$ & 0.727 \\
\hline Age & $25.41 \pm 7.94$ & $24 \pm 5.12$ & $28.23 \pm 11.49$ & 0.226 \\
\hline Socio-Economic Status & $40.68 \pm 13.50$ & $38.19 \pm 14.13$ & $45.65 \pm 10.99$ & 0.105 \\
\hline WAIS IQ & $108.13 \pm 12.73$ & $107.50 \pm 13.71$ & $109.38 \pm 10.90$ & 0.669 \\
\hline Premorbid IQ & $115.70 \pm 3.29$ & $114.82 \pm 3.01$ & $117.46 \pm 3.22$ & $0.016^{*}$ \\
\hline
\end{tabular}

Table 1D reports statistical comparisons between groups. Significant between-groups differences $(p<0.05)$ are marked with $\left(^{*}\right)$

SD: Standard Deviation; HC: Healthy Controls; PSY = Patients with Psychosis; ESD = Early Stages of Disease; FHR=familial high-risk individuals M/F: Male/Female; IQ: Intelligence Quotient; PANSS: Positive and Negative Symptoms Scale; YMRS: Young Mania Rating Scale; n.a. = not assessed

a. to investigate emotion perception, we employed the Facial Emotion Identification Test (FEIT) ([39]; details about the Italian version employed can be found at [40]); we employed a computerized FEIT version [41] in which individuals were shown 19 individuals' faces each depicting one of six different emotions (happiness, sadness, anger, surprise, fear, shame), shown one at a time for $15 \mathrm{~s}$, with $10 \mathrm{~s}$ of blank screen between each stimulus presentation. 15 photographs depict negative emotions (sadness, anger, fear, and shame), while 4 photographs depict positive emotions (happiness, and surprise). After the presentation of each stimulus, individuals were required to select which of the six emotions was depicted on the picture and to mark it on an answer form. The total test score was computed as the percentage of correct answers.

b. to investigate theory of mind, we employed The Awareness of Social Inference Test (TASIT) ([42]; details about the Italian version employed can be found at [40]). The TASIT is composed of seven scales (positive emotions, negative emotions, sincere, simple sarcasm, paradoxical sarcasm, sarcasm enriched, lie), organized into three sections: in the section "emotion recognition", individuals undergo 28 video-vignettes of professional actors enacting 
Table 2 Features entering the machine learning algorithms and their respective characterization in all study samples

\begin{tabular}{|c|c|c|c|c|}
\hline & All subjects (mean $\pm \mathrm{SD}$ ) & $\begin{array}{l}\mathrm{HC} \\
(\text { mean } \pm \mathrm{SD})\end{array}$ & $\begin{array}{l}\text { PSY } \\
(\text { mean } \pm \text { SD) }\end{array}$ & $\begin{array}{l}\text { HC vs. PSY } \\
\text { p value }\end{array}$ \\
\hline \multicolumn{5}{|l|}{ A. Discovery sample } \\
\hline PBI maternal care & $25.14 \pm 6.39$ & $25.77 \pm 5.81$ & $23.82 \pm 7.39$ & 0.144 \\
\hline PBI maternal overprot & $16.30 \pm 7.54$ & $15.21 \pm 7.09$ & $18.56 \pm 8.03$ & $0.033^{*}$ \\
\hline PBI paternal care & $20.57 \pm 7.79$ & $20.28 \pm 7.75$ & $21.18 \pm 7.94$ & 0.583 \\
\hline PBI paternal overprot & $14.97 \pm 7.22$ & $13.80 \pm 7.06$ & $17.35 \pm 7.07$ & $0.018^{*}$ \\
\hline ECR avoidance & $46.59 \pm 16.28$ & $44.06 \pm 16.64$ & $51.88 \pm 14.32$ & $0.020^{*}$ \\
\hline \multirow[t]{2}{*}{ ECR anxiety } & $65.61 \pm 21.22$ & $61.30 \pm 20.11$ & $74.62 \pm 20.92$ & $0.002^{*}$ \\
\hline & All subjects (mean $\pm \mathrm{SD}$ ) & $\begin{array}{l}\mathrm{HC} \\
(\text { mean } \pm \mathrm{SD})\end{array}$ & $\begin{array}{l}\text { ESD } \\
(\text { mean } \pm S D)\end{array}$ & $\begin{array}{l}\mathrm{HC} \text { vs. ESD } \\
\text { p value }\end{array}$ \\
\hline \multicolumn{5}{|c|}{ B. Validation clinical sample } \\
\hline PBI maternal care & $27.18 \pm 6.49$ & $28.67 \pm 5.30$ & $24.20 \pm 7.63$ & $0.002^{*}$ \\
\hline PBI maternal overprot & $16.18 \pm 6.65$ & $15.32 \pm 6.61$ & $17.90 \pm 6.49$ & 0.082 \\
\hline PBI paternal care & $22.76 \pm 8.06$ & $23.42 \pm 7.68$ & $21.43 \pm 8.74$ & 0.273 \\
\hline PBI paternal overprot & $13.30 \pm 7.09$ & $13.35 \pm 7.14$ & $13.20 \pm 7.11$ & 0.925 \\
\hline ECR avoidance & $44.37 \pm 18.26$ & $41.40 \pm 17.59$ & $50.30 \pm 18.43$ & $0.028^{*}$ \\
\hline \multirow[t]{2}{*}{ ECR anxiety } & $66.17 \pm 19.85$ & $63.43 \pm 19.58$ & $71.63 \pm 19.56$ & 0.064 \\
\hline & All subjects (mean $\pm \mathrm{SD}$ ) & $\begin{array}{l}\mathrm{HC} \\
(\text { mean } \pm \mathrm{SD})\end{array}$ & $\begin{array}{l}\text { FHR } \\
\text { (mean } \pm S D)\end{array}$ & $\begin{array}{l}\text { HC vs. FHR } \\
\text { p value }\end{array}$ \\
\hline \multicolumn{5}{|c|}{ C. Validation familial risk sample } \\
\hline PBI maternal care & $26.33 \pm 6.71$ & $25.65 \pm 6.88$ & $27.69 \pm 6.41$ & 0.368 \\
\hline PBI maternal overprot & $15.44 \pm 7.62$ & $17.27 \pm 7.01$ & $11.77 \pm 7.71$ & $0.032^{*}$ \\
\hline PBI paternal care & $23.69 \pm 6.53$ & $24.50 \pm 6.17$ & $22.08 \pm 7.18$ & 0.280 \\
\hline PBI paternal overprot & $14.28 \pm 8.17$ & $15.35 \pm 7.46$ & $12.15 \pm 9.39$ & 0.255 \\
\hline ECR avoidance & $45.21 \pm 16.42$ & $43.88 \pm 14.12$ & $47.85 \pm 20.67$ & 0.542 \\
\hline ECR anxiety & $61.51 \pm 17.81$ & $61.96 \pm 16.63$ & $60.62 \pm 20.65$ & 0.827 \\
\hline
\end{tabular}

Significant between-groups differences $(p<0.05)$ are marked with $\left(^{*}\right)$

$\mathrm{PBI}=$ Parental Bonding Instrument; $\mathrm{ECR}=$ Experiences in Close Relationships; overprot = overprotection; $\mathrm{HC}=\mathrm{Healthy}$ Controls; $\mathrm{PSY}=\mathrm{Patients}$ with $\mathrm{Psychosis;}$ $\mathrm{ESD}=$ Early Stages of Disease; FHR = Familial High Risk; $\mathrm{SD}=$ standard deviation

ambiguous scripts representing 7 basic emotions (happy, sad, surprised, angry, anxious, revolted, neutral), and at the end of each vignette they are asked to choose the perceived emotion of a given actor indicated in the answer form. The second section, social inference (minimal), allows researchers to investigate the understanding of conversational meanings that are determined by paralinguistic cues. Here, individuals are required to watch 15 video-vignettes of either sincere or sarcastic or paradoxical everyday conversational exchanges; for each vignette, individuals are asked 4 comprehension questions, respectively testing the understanding of actors' beliefs, meaning, intentions, and feelings. The last section, social inference (enriched), assesses the ability to use contextual knowledge, like visual and verbal information, to derive meaning. Individuals are asked to undergo 16 video-vignettes, each one including a literally untrue comment (see Supplementary Infor- mation, section "Results" for a full description). For each vignette, individuals are asked 4 comprehension questions, respectively testing the understanding of actors' beliefs, meaning, intentions, and feelings. For analysis purposes, we used the total number of correctly answered questions for each of the three TASIT sections.

c. To test the ability to manage emotions, i.e. "to be open to feelings, and to modulate them in oneself and others so as to promote personal understanding and growth of regulating emotions in oneself and in one's relationships with others" [43], we employed the Branch 4 (managing emotions) of the Mayer-Salovey-Caruso Emotional Intelligence Test (MSCEIT) ([43], Italian version: [44]). MSCEIT Branch 4 allows researchers to examine the ability to manage emotions by asking individuals to read short stories about an imaginary person going through an emotionally difficult situation, and then determine how effective 
several different courses of action would be for that given person in coping with the difficult emotions of the story. Individuals rate every possible action ranging from «Very ineffective», to «Very effective». MSCEIT scoring was based on the consensus scoring methods outlined in the manual [43].

Two-sample t-tests were employed to assess differences in discovery and validation samples for FEIT, TASIT, and MSCEIT total scores employed in subsequent statistical analysis (Table 3). All $\mathrm{p}$ values were $<0.05$. In the case of significant results, TASIT $p$ values were $<0.05$, False Discovery Rate (FDR) corrected for the number sections tested (i.e., 3) [45].

\section{Machine learning pipeline}

The overall machine learning strategy was carried out through the NeuroMiner software, version 1.0 (https:// github.com/neurominer-git?tab=repositories) and consisted in building a multimodal algorithm based on the six perceived parental bonding and adult attachment related-variables (i.e., PBI maternal care, PBI paternal care, PBI maternal overprotection, PBI paternal overprotection, ECR avoidance, ECR anxiety, hereby called "features", Table 2) which accurately discriminates between $\mathrm{HC}$ and PSY. With this aim, we implemented a repeated nested cross-validation strategy $(\mathrm{CV}$, Supplementary Information, section "Discussion") [32, 46, 47] to identify models that contributed most to the classification pattern separating PSY and $\mathrm{HC}$ at the inner CV level. To enforce an unbiased estimation of classification generalizability, these models were then applied to the test data at the outer CV level, which included individuals that were not used for training the classification algorithm [48]. We obtained a Support Vector Machine [49] ensemble model based on the six perceived parental bonding and adult attachment-related variables listed before. Model performance was measured using sensitivity, specificity, balanced accuracy (BAC), positive predictive value (PPV), negative predictive value (NPV), and Area-Under-the Curve (AUC) based on the class membership probability scores generated through ensemble-based majority voting in the repeated nested CV framework (Supplementary Information, section Discussion). We also assigned

Table 3 Social Cognition performance in all study samples

\begin{tabular}{|c|c|c|c|c|}
\hline & All subjects (mean $\pm S D$ ) & $\begin{array}{l}\mathrm{HC} \\
(\text { mean } \pm \mathrm{SD})\end{array}$ & $\begin{array}{l}\text { PSY } \\
(\text { mean } \pm S D)\end{array}$ & $\begin{array}{l}\text { HC vs. PSY } \\
\text { p value }\end{array}$ \\
\hline \multicolumn{5}{|l|}{ A. Discovery sample } \\
\hline FEIT \%correct & $77.82 \pm 10.66$ & $82.004 \pm 7.83$ & $69.09 \pm 10.57$ & $<0.001^{*}$ \\
\hline TASIT tot.corr. Section 1 & $24.13 \pm 3.22$ & $25.34 \pm 1.93$ & $21.62 \pm 3.97$ & $<0.001^{*}$ \\
\hline TASIT tot.corr. Section 2 & $48.37 \pm 8.45$ & $51.42 \pm 6.40$ & $41.79 \pm 8.67$ & $<0.001^{*}$ \\
\hline TASIT tot.corr. Section 3 & $49.56 \pm 7.11$ & $53.04 \pm 3.71$ & $42.38 \pm 7.07$ & $<0.001^{*}$ \\
\hline \multirow[t]{2}{*}{ MSCEIT Br4 total score } & $83.04 \pm 9.84$ & $85.75 \pm 9.47$ & $77.39 \pm 8.16$ & $<0.001^{*}$ \\
\hline & All subjects (mean $\pm S D$ ) & $\begin{array}{l}\mathrm{HC} \\
(\text { mean } \pm \mathrm{SD})\end{array}$ & $\begin{array}{l}\text { ESD } \\
(\text { mean } \pm S D)\end{array}$ & $\begin{array}{l}\mathrm{HC} \text { vs. ESD } \\
\text { p value }\end{array}$ \\
\hline \multicolumn{5}{|c|}{ B. Validation clinical sample } \\
\hline FEIT \%correct & $79.27 \pm 8.18$ & $80.43 \pm 7.21$ & $76.96 \pm 9.57$ & 0.057 \\
\hline TASIT tot.corr. Section 1 & $25.12 \pm 2.41$ & $25.40 \pm 2.33$ & $24.57 \pm 2.50$ & 0.122 \\
\hline TASIT tot.corr. Section 2 & $50.85 \pm 4.93$ & $52.20 \pm 4.17$ & $48.17 \pm 5.30$ & $<0.001^{*}$ \\
\hline TASIT tot.corr. Section 3 & $50.10 \pm 5.01$ & $51.25 \pm 3.56$ & $47.80 \pm 6.58$ & $0.011^{*}$ \\
\hline \multirow[t]{2}{*}{ MSCEIT Br4 total score } & $86.49 \pm 9.78$ & $87.44 \pm 10.01$ & $84.58 \pm 9.17$ & 0.193 \\
\hline & All subjects (mean \pm SD) & $\begin{array}{l}\mathrm{HC} \\
(\text { mean } \pm \mathrm{SD})\end{array}$ & $\begin{array}{l}\text { FHR } \\
(\text { mean } \pm S D)\end{array}$ & $\begin{array}{l}\text { HC vs. FHR } \\
\text { p value }\end{array}$ \\
\hline \multicolumn{5}{|c|}{ C. Validation familial risk sample } \\
\hline FEIT \%correct & $80.02 \pm 1.32$ & $80.03 \pm 1.36$ & $80 \pm 1.27$ & 0.942 \\
\hline TASIT tot.corr. Section 1 & $23.83 \pm 1.14$ & $24 \pm 1.30$ & $23.50 \pm 0.64$ & 0.200 \\
\hline TASIT tot.corr. Section 2 & $51.28 \pm 4.16$ & $56.50 \pm 1.85$ & $48.67 \pm 1.84$ & $<0.001^{*}$ \\
\hline TASIT tot.corr. Section 3 & $53.83 \pm 2.01$ & $54 \pm 2.42$ & $53.50 \pm 0.64$ & 0.471 \\
\hline MSCEIT Br4 total score & $82.25 \pm 5.08$ & $87.41 \pm 3.36$ & $83.93 \pm 7.04$ & $0.043^{*}$ \\
\hline
\end{tabular}

Significant between-groups differences $(\mathrm{p}<0.05)$ are marked with $\left(^{*}\right)$

$\mathrm{PBI}=$ Parental Bonding Instrument; FEIT = Facial Emotion Identification task; TASIT = The Awareness Of Social Inference Test; MSCEIT=Mayer-Salovey-Caruso Emotional Intelligence Test; $\mathrm{HC}=$ Healthy Controls; PSY = Patients with Psychosis; ESD = Early Stages of Disease; FHR = Familial High Risk; SD = standard deviation 
statistical significance to the observed classification performance of our model through permutation analysis (Supplementary, Information, sect. 5). Furthermore, to understand the importance of the input features for generating decisions (i.e., PSY or $\mathrm{HC}$ ?), we computed for each feature the probability of being selected for classification purposes within the inner $\mathrm{CV}$ loop $[50,51]$. A detailed description of our machine learning pipeline is reported in Supplementary Information, section "Discussion".

Further, we performed some sanity checks in order to exclude that our machine learning algorithm was associated with any clinical confound. Therefore, in the PSY group, we conducted Pearson's $r$ correlations between subject-specific linear SVM decision scores and, respectively, medication (expressed in chlorpromazine equivalents), level of functioning (as assessed by Global Assessment of Functioning, [52]), and age of onset. A more positive decision score suggests that a given individual is highly prototypical of the $\mathrm{HC}$ class, while a more negative decision score suggests that a given individual is highly prototypical of the PSY class.

\section{Out-of-sample validation analyses}

To investigate whether the machine learning model can discriminate between PSY and HC could have a potential prognostic validity, we externally validated the model in the validation clinical sample (Table 1B) and in the validation familial risk sample (Table 1C). With this purpose, we performed out-of-sample validation analysis by applying the SVM ensemble decision model obtained from the discovery analysis without any in-between re-training steps to both validation cohorts (i.e., ESD vs. HC, and FHR vs. HC), as already done in previous publications $[51,53]$.

\section{Association analysis between decision scores and social cognition}

To investigate whether the classification performance of our algorithm was associated with social cognition performance as a function of diagnosis, we tested the diagnosis (i.e., PSY vs. HC) x classification rate (i.e., correctly classified vs. misclassified individuals, based on the comparison between observed and predicted labels) interaction on social cognition (as measured by FEIT total score, TASIT total score, MSCEIT standardized total score). Analyses were controlled for age, gender and premorbid IQ (Supplementary Information, section "Background"). All significant $p$ values were $p<0.05$. In the case of significant results, TASIT $\mathrm{p}$ values were $<0.05$, FDR corrected for the number of sections tested (i.e., 3) [45].
Given the validation results (see Results, section "Validation familial risk sample"), this same analysis pipeline has been repeated on the validation clinical sample.

As a sanity check, to rule out any possibility that differences in terms of social cognition performance across groups (Table 3) could have influenced the classification performance of our algorithm, we performed correlation analysis on the whole discovery sample between all features which entered the machine learning algorithm, and each socio-cognitive variable of interest used for association analysis. All p values were $>0.05$, FDR corrected. Results of this sanity check are reported in Supplementary Table S2 and highlight the absence of any significant association between features entering the algorithm and socio-cognitive variables of interest.

\section{Results}

\section{Discovery sample}

ANOVA and $\chi^{2}$ analyses revealed that PSY differed significantly from $\mathrm{HC}$ in terms of age, WAIS and premorbid IQ (all $p<0.001$, Table 1A), as well as on all measures of social cognition (all $p<0.001$, Table 3A), with PSY performing significantly worse than $\mathrm{HC}$. The machine learning model based on parental bonding and adult attachment-related variables correctly discriminated PSY from $\mathrm{HC}$ with a cross-validated BAC of $72.2 \%$ (sensitivity: $82.4 \%$; specificity: $62.2 \%$; Area Under the Curve: 0.71 ) and was significant at $p<0.001$. Detailed statistics of all individual classification models are reported in Table 4. When computing the probability of each feature of being selected for classification purposes within the inner CV loop, we observed that the features with the highest probability (i.e., those that were selected the most for discrimination purposes within the CV framework) were PBI maternal care, ECR avoidance, and PBI overprotection (Fig. 1). In PSY, we found no association between SVM decision scores and, respectively, medication, GAF score and age of onset (respectively, $p=0.25, p=0.52$, $p=0.87)$.

\section{Validation samples Validation clinical sample}

ANOVA and $x^{2}$ revealed that ESD differed significantly from $\mathrm{HC}$ in terms of gender distribution $(p=0.007$, Table 1B) and of social inference performance (minimal, $p<0.001$; enriched, $p=0.011$ ) as measured by TASIT sections "Methods" and "Results" (Table 3B), with ESD performing worse than HC. Results from the out-of-sample validation analysis discriminating between ESD and $\mathrm{HC}$ based on the model classifying PSY from HC (Results section "Discovery sample") revealed that the parental bonding and adult attachment-related model discriminating between PSY and $\mathrm{HC}$ also discriminated between 


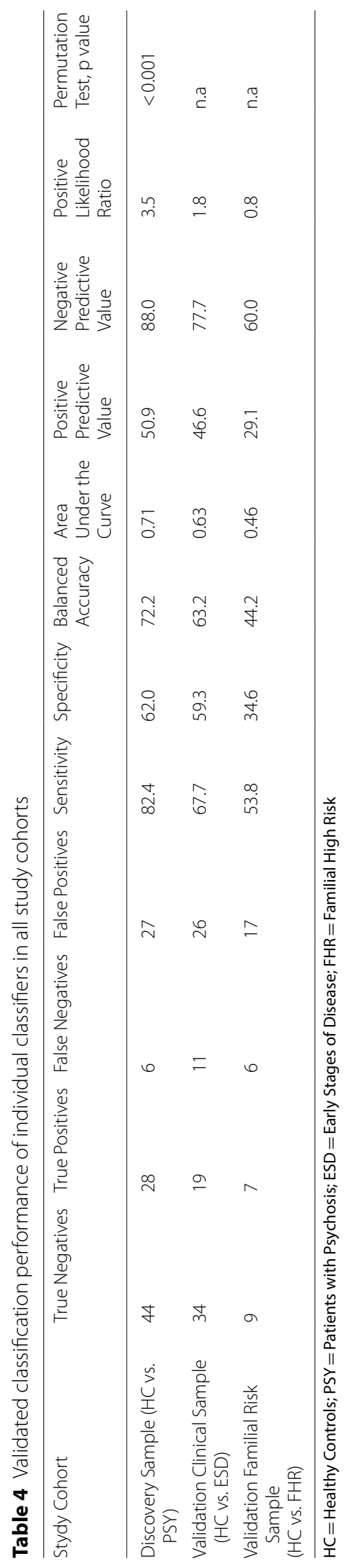




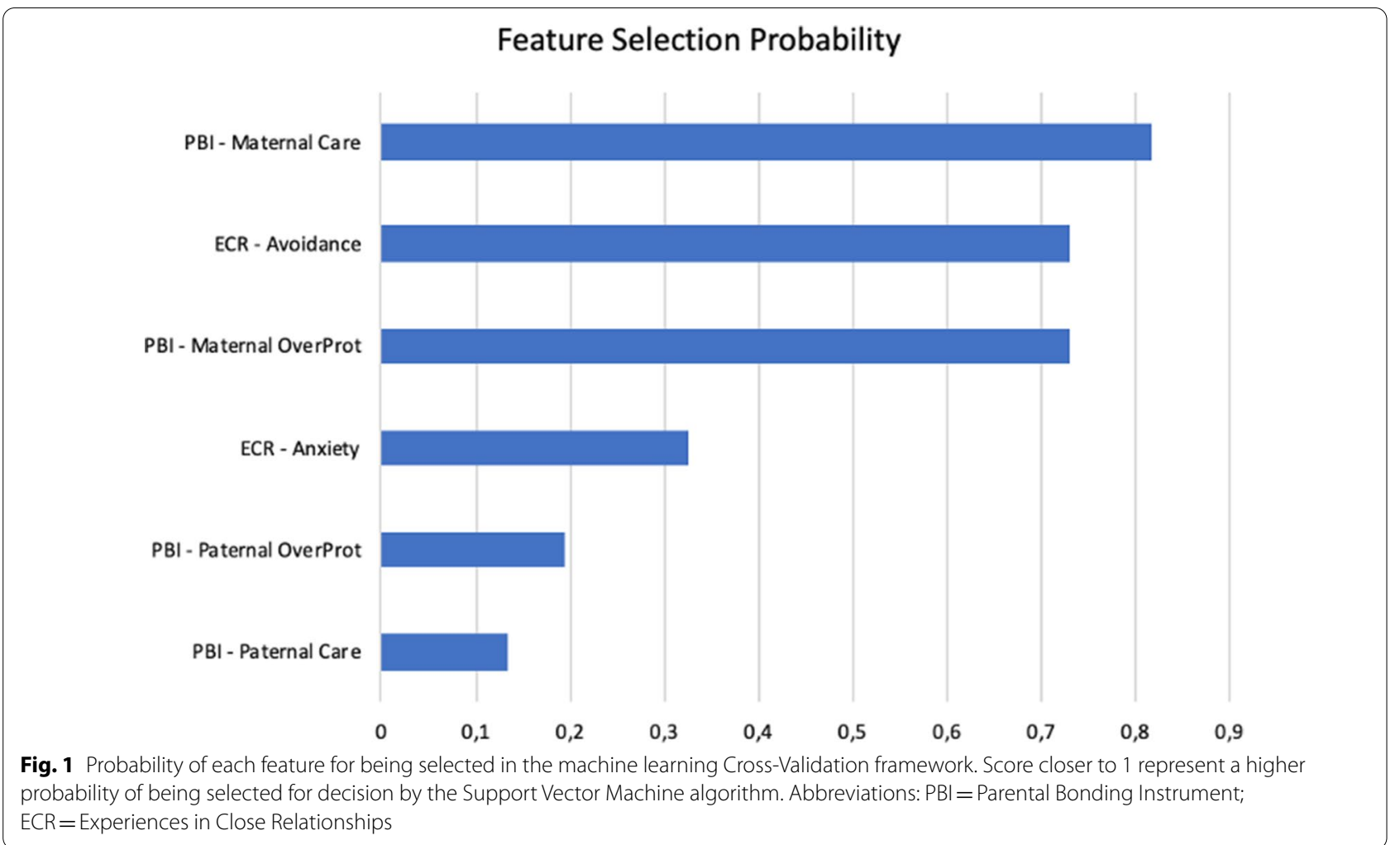

ESD and HC with a cross-validated BAC of $63.5 \%$ (sensitivity: 67.7\%; specificity: 59.3\%; Area Under the Curve: 0.65 , Table 4).

\section{Validation familial risk sample}

ANOVA and $\chi^{2}$ revealed that FHR differed significantly from HC in terms of IQ $(p=0.016$, Table $1 C)$ and of minimal social inference (TASIT section "Methods", $p<0.001$, Table 3C) and managing of emotions abilities (MSCEIT Branch 4, $p=0.043$, Table 3C), with FHR performing worse than HC. Results from the out-of-sample validation analysis discriminating between FHR and $\mathrm{HC}$ based on the model classifying PSY from HC revealed that the parental bonding and adult attachment-related model discriminating between PSY and HC did not significantly discriminate between ESD and HC (cross-validated BAC: $44.2 \%$, Table 4).

\section{Association analysis between decision scores and social cognition \\ Discovery sample}

General linear models revealed a significant diagnosis $x$ classification rate interaction on FEIT percentage of correct answers $(\mathrm{F}=5.11, p=0.02$, Fig. 2$)$, such that the misclassified PSY (i.e., the PSY individuals that the algorithm wrongly identified as $\mathrm{HC}$ ) had higher percentage of correct responses than the correctly classified PSY (i.e., the PSY individuals that the algorithm correctly identified as PSY) $(p=0.03)$, while no differences between the correctly classified and the misclassified $\mathrm{HC}$ individuals were found $(p=0.58)$. We also found a significant diagnosis $\mathrm{x}$ classification rate interaction on MSCEIT Branch 4 total score $(\mathrm{F}=6.39, p=0.02$, Fig. 3$)$, such that the misclassified $\mathrm{HC}$ (i.e., the $\mathrm{HC}$ individuals that the algorithm wrongly identified as PSY) had lower MSCEIT total score than the correctly classified $\mathrm{HC}$ (i.e., the $\mathrm{HC}$ individuals that the algorithm correctly identified as $\mathrm{HC}, p=0.04$ ). On the other hand, no differences between the correctly classified and the misclassified PSY individuals were found $(p=0.09)$. No significant interactions were found on TASIT section-related total scores (respectively, $p=0.45, p=0.31, p=0.15$ ).

\section{Validation clinical sample}

General linear models revealed a significant diagnosis $\mathrm{x}$ classification rate interaction on MSCEIT Branch 4 total score $(\mathrm{F}=4.74, p=0.03$, Fig. 4$)$, such that the misclassified ESD (i.e., the ESD individuals that the algorithm wrongly identified as HC) had higher MSCEIT total score than the correctly classified ESD (i.e., the ESD individuals that the algorithm correctly identified as ESD) $(p=0.02)$, while no differences between the correctly classified and 


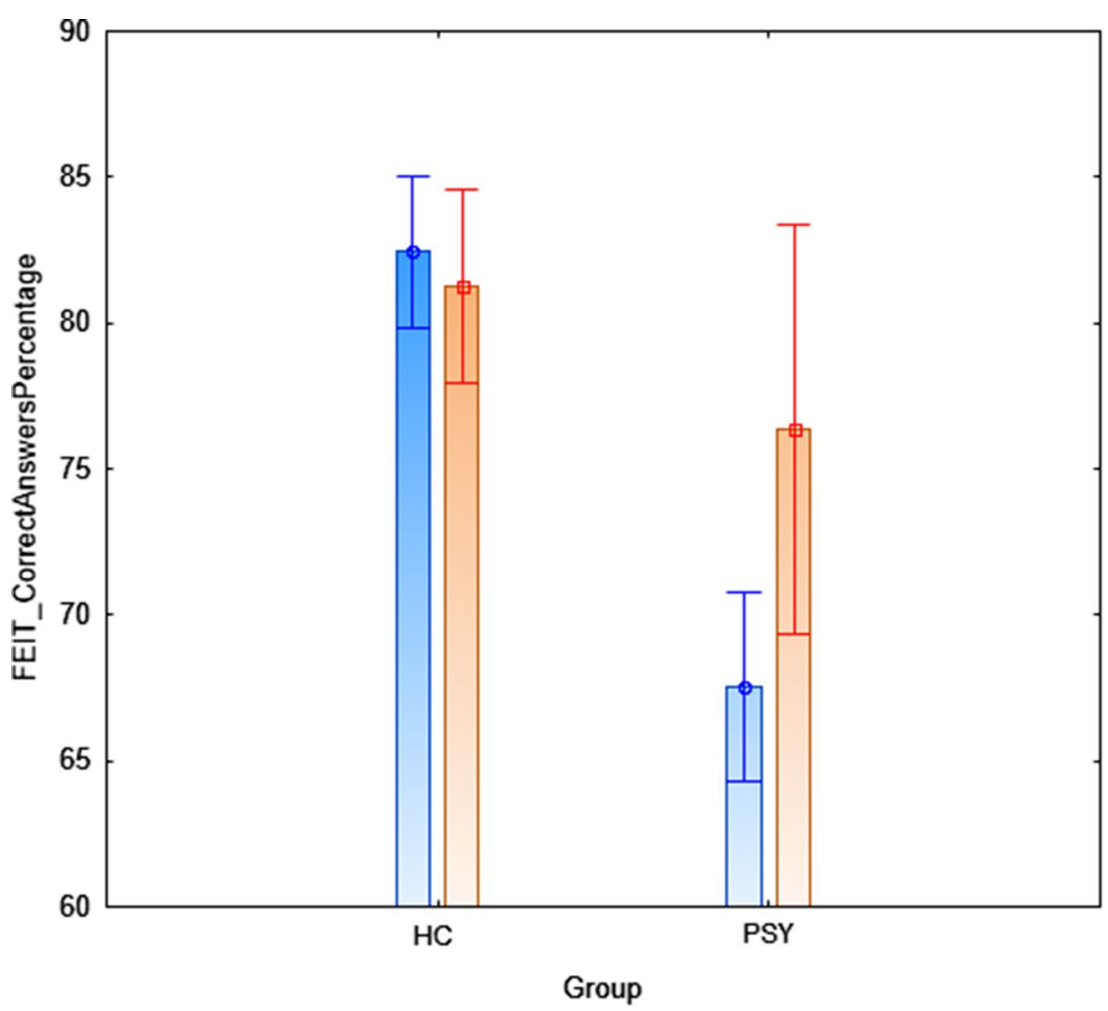

classified

misclassified

Fig. 2 Depicting of the group x classification rate interaction on FEIT percentage of total correct responses in the discovery sample. Abbreviations: $\mathrm{FEIT}=$ Facial Emotion Identification Test; PSY = Individuals diagnosed with Psychosis; $\mathrm{HC}=$ Healthy Controls

the misclassified $\mathrm{HC}$ individuals were found $(p=0.74)$. No significant interactions were found on FEIT percentage of correct responses $(p=0.40)$ and on TASIT section-related total scores (respectively, $p=0.06, p=0.16$, $p=0.51)$.

\section{Discussion}

In this study, we aimed at discriminating between PSY and HC within a machine learning framework based on perceived parenting and attachment-related variables, at externally validating this classification model in cohorts reflecting early stages of psychosis (i.e., ESD individuals), as well as its familial risk (i.e., FHR individuals), and at understanding across these cohorts whether algorithmic decisions were associated with social cognition impairments. To the best of our knowledge, our results for the first time offer preliminary insights about the machine learning-based classification ability of perceived quality of parenting and attachment style variables, revealing that this set of variables correctly discriminates between PSY and $\mathrm{HC}$ with a $72.2 \% \mathrm{BAC}$ and significance. These findings are in line with previous literature suggesting the role of a perceived negative family environment [54] and insecure attachment [16] in the vulnerability for psychosis. Notably, the most reliable features for classification purposes were PBI maternal care, ECR attachment avoidance and PBI maternal overprotection. The PBI results are in line with previous evidence showing that expressed emotions, communication deviance, and rearing within the family have all been previously associated with the prognosis of psychosis [54]. As concerns attachment avoidance, it has been previously associated with both positive and negative symptoms in PSY [24], and with psychotic symptoms, paranoia, endorsement of delusional experiences, negative affect regulation and social anhedonia in non-clinical samples $[25,55]$. Nevertheless, these results should be taken with caution. Indeed, the risk pathways of psychosis are complex and heterogeneous, and reflect complex interplays between multiple genetic, environmental and neurocognitive characteristics [23]. In this framework, our results do not suggest that perceived negative parenting and attachment insecurities are sufficient causative factors for psychosis. Rather, they highlight their potential role as general vulnerability-to-psychosis factors[16], whose effect may be amplified by other more specific schizophrenia and bipolar disorder-related genetic and 


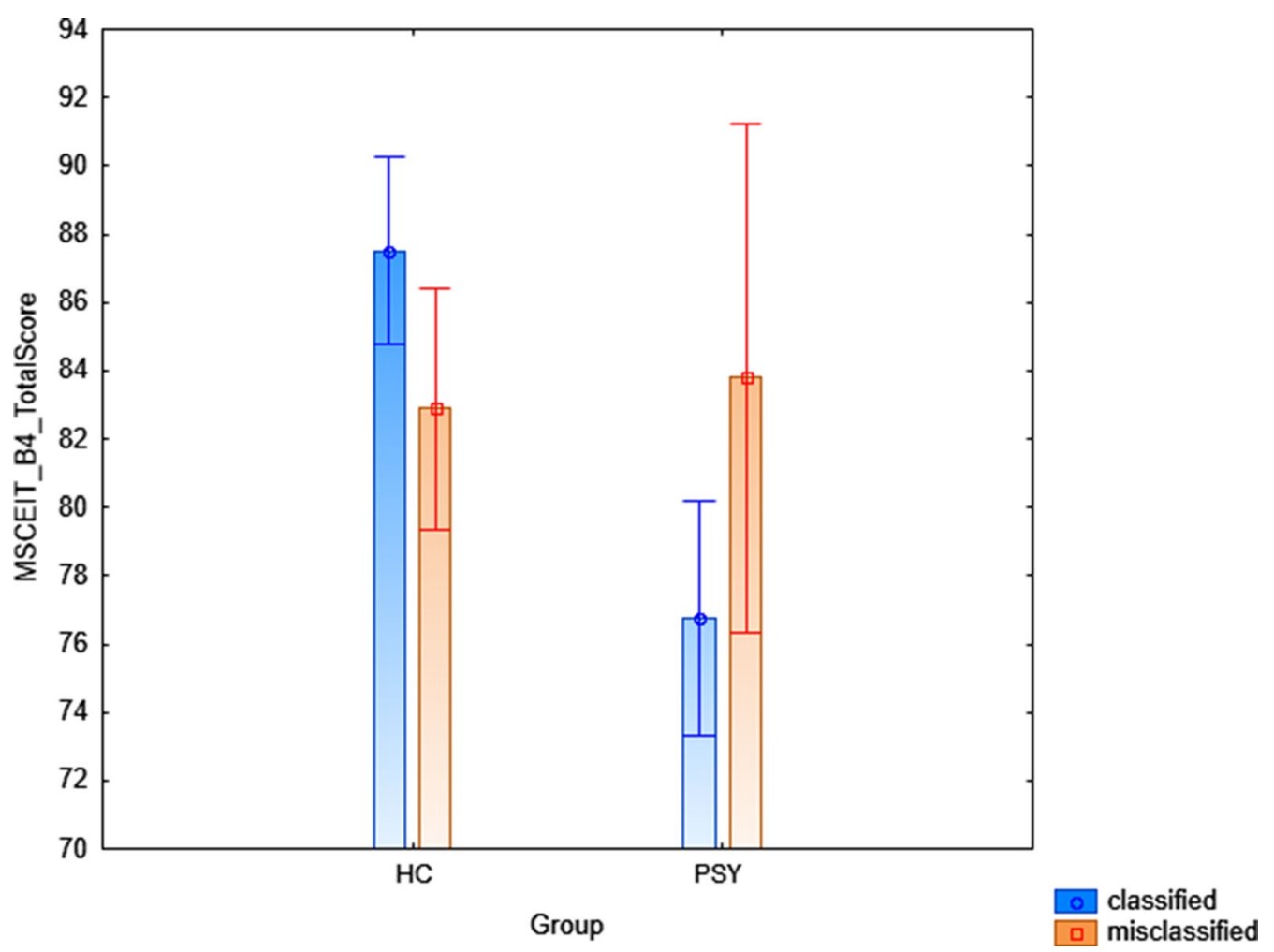

Fig. 3 Depicting of the group x classification rate interaction on MSCEIT total score in the discovery sample. Abbreviations: FEIT=Mayer Salovey Caruso Emotional Intelligence Test; PSY = Individuals diagnosed with Psychosis; $\mathrm{HC}=$ Healthy Controls

environmental factors, possibly leading to cognitive biases in reality interpretation [23].

This view is further corroborated by the fact that our perceived parenting and attachment-related model correctly discriminated also unseen ESD and $\mathrm{HC}$ individuals with $63.5 \%$ BAC. The $8.7 \%$ BAC drop observed in comparison with the discovery sample's performance may be explained by both clinical reasons (i.e., the ESD cohort is composed by individuals either at their first episode of psychosis or depression or by individuals at high clinical risk for psychosis, see Supplementary Information, section "Background) and demographic differences between the discovery and the validation clinical cohorts (Table 1). Despite these differences, these findings show that our model not only achieves high diagnostic performance, but it also carries an intrinsic early identification potential. Thus, they may speak in favor of the possibility of specifically targeting parenting and attachment-related factors into early identification and prevention programs, especially in terms of promotion of attachment security as a key general resilience factor [56]. Nevertheless, future studies in larger and geographically diverse samples are warranted to realistically understand the potential of translation into clinical practice of our results.
It should be also noted that the model we generated in the PSY and HC discovery sample discriminated between FHR and HC at chance-level, thus suggesting that the general vulnerability-to-psychosis role of parenting and attachment characteristics might act only in the "late" portion of psychosis risk (as testified by the validation in ESD individuals), but not in "early" portions of psychosis risk. Indeed, FHR individuals do not have any clinical impairment or other risk conditions, but their PSY first-degree relative. This view is supported by previous evidence in which significant avoidance differences in attachment anxiety and avoidance have been found between individuals diagnosed with schizophrenia and their unaffected siblings, but not between their siblings and controls [22]. Another aspect that should be taken into consideration is that the PBI and ECR instruments, from which the features entering the machine learning algorithm were extracted, are self-report questionnaires. Despite evidence testifying that attachment self-reports measures are highly reliable in reflecting individuals' actual attachment dispositions [57, 58], it can't be excluded that the internal working models of attachment experiences, as well as the perception of the parenting received, are affected by biases in reality interpretation 


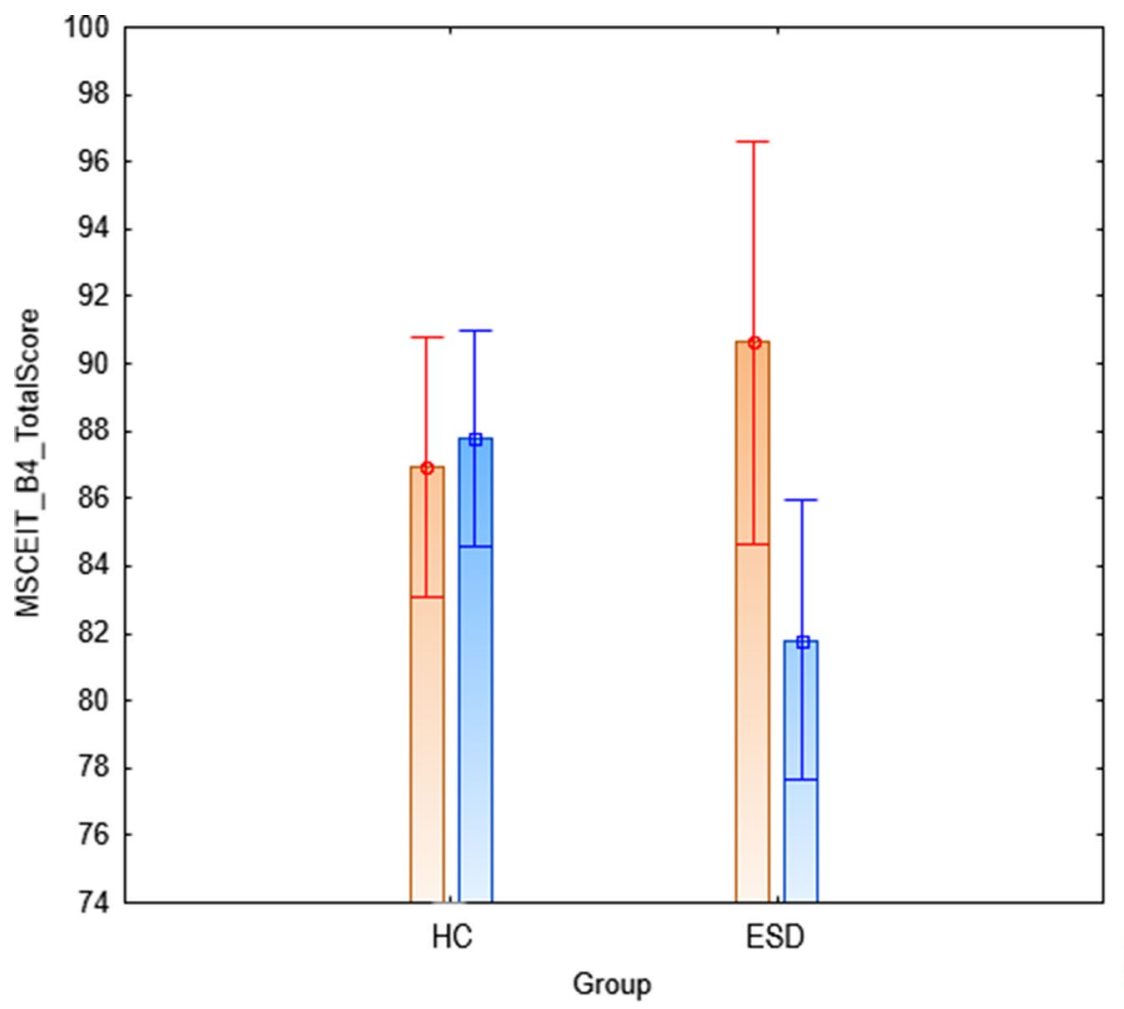

classified misclassified

Fig. 4 Depicting of the group x classification rate interaction on MSCEIT total score in the validation clinical sample. Abbreviations: FEIT = Mayer Salovey Caruso Emotional Intelligence Test; ESD = Early Stages of Disease; $\mathrm{HC}=$ Healthy Controls

associated with illness experience at any stage (i.e., in both PSY and ESD individuals), which should not occur when only familial or genetic risk conditions are present. Indeed, a previous contribution [59] showed that individuals with an ongoing depressive disorder had more negative recollections of parenting experiences than those who remitted from a depressive disorder. This evidence corroborates the hypothesis that the experience of a mental illness is associated with biases in the interpretation of memories, although it is difficult to attribute any causality or directionality to this association. Nevertheless, our findings testify the urgency of implementing psychoeducation actions in psychosis, potentially through the combination of social skills trainings and emotional/ motivational support to all family members, aimed at improving illness knowledge, resilience and coping skills after adverse childhood experiences. These actions would support not only individuals suffering from psychosis but would also more likely alleviate the illness-related emotional burden of their caregivers.

We also found a significant interaction between group and classification rate on social cognition performance in the cohorts in which our models showed good classification power, which speaks in favor of targeting social cognition deficits in early identification and intervention programs through social skills trainings. Indeed, in PSY and HC individuals from the discovery sample, this interaction was present on both FEIT and MSCEIT total scores. For FEIT, PSY that the algorithm misclassified as HC had higher emotion perception and ability to manage emotions, compared with PSY correctly classified as cases, and not as controls. For MSCEIT, $\mathrm{HC}$ individuals that the algorithm misclassified as PSY had lower emotion perception and managing of emotions abilities, compared with $\mathrm{HC}$ individuals that correctly classified as controls, and not as cases. We found the interaction also in the ESD and $\mathrm{HC}$ validation clinical sample, but only on MSCEIT total score, such that misclassified ESD had higher managing of emotions ability compared with correctly classified ESD. In both samples, no group $x$ classification rate interaction was found on theory of mind abilities. Taken together, these results support the view for which parenting and attachment experiences guide how the social world is appraised [15] to the extent that their association with social cognition abilities is significant. Notably, this association is present on both basic and complex emotional aspects of social cognition as a function of PSY diagnosis, and 
only on cognitive-emotional aspects in ESD individuals. Indeed, emotion perception (i.e., the conscious recognition of basic emotions on facial stimuli) has repeatedly been found as impaired in PSY [60, 61], and previous evidence revealed an association between attachment style and both behavioral and brain correlates of emotion recognition [62]. This interaction was significant only in PSY, most likely because this basic emotion ability tends to worsen in the level of impairments along with disease chronicity and symptom severity $[63,64]$. Thus, it may be that the lack of interaction on the FEIT score in ESD is due to their more preserved emotion recognition abilities. On the other hand, the presence of a significant group by classification rate interaction in both PSY and ESD on MSCEIT score is consistent with the fact that parenting and attachment-related factors significantly modulate affect regulation at a more complex level since the early stages of psychosis $[65,66]$. The ability to manage emotions, indeed, is one of the four emotional intelligence branches and represents the ability of individuals to handle (both at the thought and behavior levels), their own emotions effectively [67]. Consistently, a core concept of attachment theory is that attachment style strongly influences the appraisal of social cues, thus modulating affect regulation from childhood to adulthood [15].

\section{Limitations}

This study has some limitations. First of all, the small sample sizes across cohorts strongly limit the generalizability of our findings, as they may be overfitted $[68,69]$. Second, the use of a retrospective perceived maternal care measure and of a self-report attachment questionnaire could reflect false memories or even re-interpretation of the type of care received [70]. However, previous literature has indicated that both measures are stable over time [57-59, 71], suggesting that they may overall constitute reliable measures. Third, the cross-sectional nature of this study does not allow us to give any realistic prognostic insight into psychosis and its early stages based on these findings, or to speculate on whether the experience of a mental illness impacts on the perception of negative childhood experiences, or vice versa. Longitudinal studies are warranted to investigate the prognostic relevance of our model.

\section{Conclusions}

Despite the difficulty in attributing any causality to the association between psychosis and perceptions of negative childhood experiences, our results support the role of perceived negative parenting and attachment insecurity as general vulnerability characteristics in psychosis and its early phases, both because of their good classification power and because of their association with key socio-cognitive psychosis phenotypes. In this view, they improve the understanding of psychosis environmental risk pathways. Furthermore, if externally validated in larger cohorts, they offer intriguing clinical insights about the possibility of promoting positive parenting and attachment security as psychosis resilience factors within early identification and early intervention programs, especially when other more psychosisspecific environmental risk factors (e.g., childhood adverse events, low socioeconomic status, an affected first-degree relative [56]) are present.

\section{Abbreviations}

BAC: Balanced accuracy; CV: Cross-validation; ESD: Early stages of disease; FEIT: Facial emotion identification task; FHR: Familial high risk; HC: Healthy controls; MSCEIT: Mayer-Salovey-Caruso emotional intelligence test; PBI: Parental bonding instrument; PSY: Individuals diagnosed with Psychosis; SD: Standard deviation; TASIT: The awareness of social inference test.

\section{Supplementary Information}

The online version contains supplementary material available at https://doi. org/10.1186/s40359-021-00552-3.

Additional file 1. Antonucci LA, et al. - Supplementary Information.

\section{Acknowledgements}

We are grateful to Dr. Raffaella Romano, Dr. Annamaria Porcelli, and Dr. Marina Mancini for contributing to data collection, to Dr. Enrico D'Ambrosio for supervising participants' recruitments, to Prof. Pasquale Musso for the crucial insights, and to all the people who took part in this research.

\section{Authors' contributions}

LAA: conception and design of the work, analysis and interpretation of data, manuscript drafting; AR: analysis and interpretation of data; BG, MP, GC: data acquisition; GP: interpretation of data, critical revision of the manuscript; AR, GB: critical revision of the manuscript; AB: supervision, critical revision of the manuscript. All authors have approved the submitted version and have agreed to both be personally accountable for the author's contributions and to ensure that questions related to the accuracy or integrity of any part of the work, even ones in which the author was not personally involved, are appropriately investigated, resolved, and the resolution documented in the literature. All authors read and approved the final manuscript.

\section{Funding}

This study was supported from the Apulia Region funding "Early identification of psychiatric risk: a longitudinal study on endophenotypes involved in the psychosis and bipolar disorder risk" (PI: AB), and from the Structural European Funding of the Italian Minister of Education and Research (Attraction and International Mobility-AIM-action, grant agreement No 1859959). The AIM action also funds LAA's salary. GP's position is funded by the European Union's Horizon 2020 research and innovation programme under the Marie Sklodowska-Curie grant agreement No 798181. This paper reflects only the author's views and the European Union and Research Executive Agency are not liable for any use that may be made of the information contained therein. All other authors declare no biomedical financial interests and no potential conflicts of interest. The funding bodies had no role in study design, data collection, and analysis, decision to publish, or preparation of the manuscript.

\section{Availability of data and materials}

The datasets used and/or analyzed during the current study are available from the corresponding author on reasonable request. 


\section{Declarations}

\section{Ethics approval and consent to participate}

All procedures performed in this study were in accordance with the ethical standards of the institutional and/or national research committee and with the 2013 Helsinki Declaration and its later amendments or comparable ethical standards. Informed consent was obtained from all participants included in the study and, in case of minors, also from their parents or caregivers. The study protocol has been approved by the Local Ethic Committee of the Bari University Hospital (study protocol n. 4754). Written informed consent has been obtained by each individual who took part in the study if aged above 18 years old. In the case of individuals aged below 18 years old, written informed consent has been obtained by both the participant and his/her parents.

\section{Consent for publication}

Not applicable.

\section{Competing interests}

$A B$ has received lecture fees from Otsuka, Janssen, Lundbeck, and consultant fees from Biogen. GB has received lecture fees by Janssen and Lundbeck. AR has received travel fees from Lundbeck. All other authors declare no conflicts of interest.

\section{Author details}

1 Department of Education, Psychology, Communication, University of Bari Aldo Moro, Via Scipione Crisanzio 42, 70122 Bari, Italy. ${ }^{2}$ Department of Basic Medical Science, Neuroscience and Sense Organs, University of Bari Aldo Moro, Bari, Italy. ${ }^{3}$ Lieber Institute for Brain Development, Johns Hopkins Medical Campus, Baltimore, MD, USA. ${ }^{4}$ Psychiatry Unit, Bari University Hospital, Bari, Italy.

Received: 9 September 2020 Accepted: 16 March 2021 Published online: 23 March 2021

\section{References}

1. Vancampfort D, Firth J, Schuch FB, Rosenbaum S, Mugisha J, Hallgren M, Probst M, Ward PB, Gaughran F, De Hert M, et al. Sedentary behavior and physical activity levels in people with schizophrenia, bipolar disorder and major depressive disorder: a global systematic review and meta-analysis. World Psychiatry. 2017;16(3):308-15.

2. Bowie CR, Depp C, McGrath JA, Wolyniec P, Mausbach BT, Thornquist MH, Luke J, Patterson TL, Harvey PD, Pulver AE. Prediction of real-world functional disability in chronic mental disorders: a comparison of schizophrenia and bipolar disorder. Am J Psychiatry. 2010;167(9):1116-24.

3. Lomholt LH, Andersen DV, Sejrsgaard-Jacobsen C, Ozdemir CM, Graff C, Schjerning O, Jensen SE, Straszek SPV, Licht RW, Grontved S, et al. Mortality rate trends in patients diagnosed with schizophrenia or bipolar disorder: a nationwide study with 20 years of follow-up. Int J Bipolar Disord. 2019:7(1):6.

4. Nordentoft M, Wahlbeck K, Hallgren J, Westman J, Osby U, Alinaghizadeh H, Gissler M, Laursen TM. Excess mortality, causes of death and life expectancy in 270,770 patients with recent onset of mental disorders in Denmark, Finland and Sweden. PLoS ONE. 2013;8(1):e55176.

5. Bowie CR, Best MW, Depp C, Mausbach BT, Patterson TL, Pulver AE, Harvey PD. Cognitive and functional deficits in bipolar disorder and schizophrenia as a function of the presence and history of psychosis. Bipolar Disord. 2018;20(7):604-13.

6. Bora E, Pantelis C. Social cognition in schizophrenia in comparison to bipolar disorder: a meta-analysis. Schizophr Res. 2016;175(1-3):72-8.

7. Bellivier F, Geoffroy PA, Scott J, Schurhoff F, Leboyer M, Etain B. Biomarkers of bipolar disorder: specific or shared with schizophrenia? Front Biosci (Elite Ed). 2013;5:845-63.

8. Dean K, Murray RM. Environmental risk factors for psychosis. Dialogues Clin Neurosci. 2005;7(1):69-80.

9. Demjaha A, MacCabe JH, Murray RM. How genes and environmental factors determine the different neurodevelopmental trajectories of schizophrenia and bipolar disorder. Schizophr Bull. 2012;38(2):209-14.
10. Popovic D. RA, Dwyer D.B., Antonucci L.A., Eder J., Sanfelici R., KambeitzIlankovic L., Oztuerk O.F., Dong M.S., Paul R., Paolini M., Hedderiche D., Haidl T., Kambeitz J., Ruhrmann S., Chisholm K., Schultze-Lutter F., Falkai P., Pergola G., Blasi G., Bertolino A., Lencer R., Dannlowski U., Upthergrove R., Salokangas R.K.R., Pantelis C., Meisenzahl E., Wood S.J., Brambilla P., Borgwardt S., Koutsouleris N.: Traces of trauma: a multivariate pattern analysis of childhood trauma, brain structure, and clinical phenotypes. Biol Psychiat 2020.

11. Chamberlain C, Gee G, Harfield S, Campbell S, Brennan S, Clark Y, Mensah F, Arabena K, Herrman H, Brown S, et al. Parenting after a history of childhood maltreatment: a scoping review and map of evidence in the perinatal period. PLoS ONE. 2019;14(3):e0213460.

12. van IMH, Bakermans-Kranenburg MJ: Bridges across the intergenerational transmission of attachment gap. Curr Opin Psychol 2019, 25:31-36.

13. Bowlby J. Attachment and loss. New York: Basic Books; 1980.

14. Bartholomew K, Horowitz LM. Attachment styles among young-adults: a test of a 4-category model. J Pers Soc Psychol. 1991;61(2):226-44.

15. Collins NL, Feeney BC. Working models of attachment shape perceptions of social support: evidence from experimental and observational studies. J Pers Soc Psychol. 2004:87(3):363-83.

16. Mikulincer M, Shaver PR. An attachment perspective on psychopathology. World Psychiatry. 2012;11(1):11-5.

17. Mikulincer M, Shaver PR. Attachment orientations and emotion regulation. Curr Opin Psychol. 2019;25:6-10.

18. Mikulincer M, Shaver PR. Attachment, group-related processes, and psychotherapy. Int J Group Psychother. 2007;57(2):233-45.

19. Mikulincer M, Gillath $\mathrm{O}$, Shaver PR. Activation of the attachment system in adulthood: threat-related primes increase the accessibility of mental representations of attachment figures. J Pers Soc Psychol. 2002;83(4):881-95.

20. Antonucci LA, Taurisano P, Coppola G, Cassibba R. Attachment style: The neurobiological substrate, interaction with genetics and role in neurodevelopmental disorders risk pathways. Neurosci Biobehav Rev. 2018;95:515-27.

21. Sheinbaum T, Kwapil TR, Ballespi S, Mitjavila M, Chun CA, Silvia PJ, Barrantes-Vidal N. Attachment style predicts affect, cognitive appraisals, and social functioning in daily life. Front Psychol. 2015;6:296.

22. Pos K, Bartels-Velthuis AA, Simons CJ, Korver-Nieberg N, Meijer CJ, de Haan L. Group: Theory of Mind and attachment styles in people with psychotic disorders, their siblings, and controls. Aust N Z J Psychiatry. 2015:49(2):171-80.

23. Howes OD, Murray RM. Schizophrenia: an integrated sociodevelopmental-cognitive model. Lancet. 2014;383(9929):1677-87.

24. Carr SC, Hardy A, Fornells-Ambrojo M. Relationship between attachment style and symptom severity across the psychosis spectrum: a metaanalysis. Clin Psychol Rev. 2018;59:145-58.

25. Lavin R, Bucci S, Varese F, Berry K. The relationship between insecure attachment and paranoia in psychosis: a systematic literature review. $\mathrm{Br} J$ Clin Psychol. 2020;59(1):39-65.

26. Berry K, Wearden A, Barrowclough C. Adult attachment styles and psychosis: an investigation of associations between general attachment styles and attachment relationships with specific others. Soc Psychiatry Psychiatr Epidemiol. 2007;42(12):972-6.

27. Berry K, Barrowclough C, Wearden A. A review of the role of adult attachment style in psychosis: unexplored issues and questions for further research. Clin Psychol Rev. 2007;27(4):458-75.

28. Ponizovsky AM, Vitenberg E, Baumgarten-Katz I, Grinshpoon A. Attachment styles and affect regulation among outpatients with schizophrenia: relationships to symptomatology and emotional distress. Psychol Psychother. 2013;86(2):164-82.

29. Ponizovsky AM, Drannikov A. Contribution of attachment insecurity to health-related quality of life in depressed patients. World J Psychiatry. 2013;3(2):41-9.

30. Dwyer DB, Falkai P, Koutsouleris N. Machine learning approaches for clinical psychology and psychiatry. Annu Rev Clin Psychol. 2018;14:91-118.

31. Goodman SN. A comment on replication, p-values and evidence. Stat Med. 1992:11(7):875-9.

32. Koutsouleris N, Kahn RS, Chekroud AM, Leucht S, Falkai P, WobrockT, Derks EM, Fleischhacker WW, Hasan A. Multisite prediction of 4-week and 52-week treatment outcomes in patients with first-episode psychosis: a machine learning approach. Lancet Psychiatry. 2016;3(10):935-46. 
33. Koutsouleris N, Riecher-Rossler A, Meisenzahl EM, Smieskova R, Studerus E, Kambeitz-Ilankovic L, von Saldern S, Cabral C, Reiser M, Falkai P, et al. Detecting the psychosis prodrome across high-risk populations using neuroanatomical biomarkers. Schizophr Bull. 2015;41(2):471-82.

34. First M. B. SR, Gibbon M., Williams, J.: Structured Clinical Interview for Axis I Disorders-Patient Edition. 1996.

35. Parker G. The parental bonding instrument. A decade of research. Soc Psychiatry Psychiatr Epidemiol 1990, 25(6):281-282.

36. Scinto AMMG, Kalyvoka A, Daneluzzo E, Rossi A. The use of the Italian version of the Parental Bonding Instrument (PBI) in a clinical sample and in a student group: an exploratory and confirmatory factor analysis study. Epidemiol Psichiatr Soc. 1999;8(4):276-83.

37. Brennan KA CC, Shaver PR. In: Simpson JA, Rholes WS: Self-report measurement of adult attachment: an integrative overview. In: Attachment theory and close relationships. edn. Edited by Press NYG; 1998.

38. Picardi AVP, Toni A, D'Amico R, Bitetti D, Pasquini P. Further evidence of the validity of the Italian version of the questionnaire "Experiences in Close Relationships" (ECR), a self-report instrument to assess adult attachment. Ital J Psychopath. 2002;8(3):282-94.

39. Kerr SL, Neale JM. Emotion perception in schizophrenia: specific deficit or further evidence of generalized poor performance? J Abnorm Psychol. 1993;102(2):312-8.

40. Rocca P, Galderisi S, Rossi A, Bertolino A, Rucci P, Gibertoni D, Montemagni C, Sigaudo M, Mucci A, Bucci P, et al. Social cognition in people with schizophrenia: a cluster-analytic approach. Psychol Med. 2016;46(13):2717-29.

41. Erol A, Putgul G, Kosger F, Ersoy B. Facial emotion recognition in schizophrenia: the impact of gender. Psychiatry Investig. 2013;10(1):69-74

42. McDonald S, Bornhofen C, Shum D, Long E, Saunders C, Neulinger K. Reliability and validity of The Awareness of Social Inference Test (TASIT): a clinical test of social perception. Disabil Rehabil. 2006;28(24):1529-42.

43. Mayer JDSP, Caruso DR. Mayer-Salovey-Caruso Emotional Intelligence Test (MSCEIT): Toronto. Ontario: Multi-Health Systems, Inc.; 2002.

44. D'Amico A CA: Traduzione ed adattamento italiano del Mayer-SaloveyCaruso Emotional Intelligence Test (MSCEIT). Firenze, Italy: OS; 2011.

45. Benjamini YHY. Controlling the false discovery rate: a practical and powerful approach to multiple testing. J Roy Stat Soc: Ser B (Methodol). 1995;57(1):289-300.

46. Antonucci LA, Penzel N, Pergola G, Kambeitz-Ilankovic L, Dwyer D, Kambeitz J, Haas SS, Passiatore R, Fazio L, Caforio G, et al. Multivariate classification of schizophrenia and its familial risk based on load-dependent attentional control brain functional connectivity. Neuropsychopharmacology. 2020;45(4):613-21

47. Koutsouleris N, Wobrock T, Guse B, Langguth B, Landgrebe M, Eichhammer P, Frank E, Cordes J, Wolwer W, Musso F, et al. Predicting response to repetitive transcranial magnetic stimulation in patients with schizophrenia using structural magnetic resonance imaging: a multisite machine learning analysis. Schizophr Bull. 2018;44(5):1021-34.

48. Ruschhaupt M, Huber W, Poustka A, Mansmann U: A compendium to ensure computational reproducibility in high-dimensional classification tasks. Statistical Applications in Genetics and Molecular Biology 2004, 3:Article37.

49. Noble WS. What is a support vector machine? Nat Biotechnol. 2006;24(12):1565-7.

50. Pergola G, Trizio S, Di Carlo P, Taurisano P, Mancini M, Amoroso N, Nettis MA, Andriola I, Caforio G, Popolizio T, et al. Grey matter volume patterns in thalamic nuclei are associated with familial risk for schizophrenia. Schizophr Res. 2017;180:13-20.

51. Antonucci LA, Pergola G, Pigoni A, Dwyer D, Kambeitz-Ilankovic L, Penzel N, Romano R, Gelao B, Torretta S, Rampino A, et al. A pattern of cognitive deficits stratified for genetic and environmental risk reliably classifies patients with schizophrenia from healthy control subjects. Biol Psychiatry. 2020;87(8):697-707.

52. Hall RC. Global assessment of functioning: a modified scale. Psychosomatics. 1995;36(3):267-75.

53. Koutsouleris N, Kambeitz-Ilankovic L, Ruhrmann S, Rosen M, Ruef A, Dwyer DB, Paolini M, Chisholm K, Kambeitz J, Haidl T, et al. Prediction models of functional outcomes for individuals in the clinical high-risk state for psychosis or with recent-onset depression: a multimodal, multisite machine learning analysis. JAMA Psychiatry. 2018;75(11):1156-72.

54. de Sousa P, Varese F, Sellwood W, Bentall RP. Parental communication and psychosis: a meta-analysis. Schizophr Bull. 2014;40(4):756-68.

55. Gumley Al, Taylor HE, Schwannauer M, MacBeth A. A systematic review of attachment and psychosis: measurement, construct validity and outcomes. Acta Psychiatr Scand. 2014;129(4):257-74.

56. Harder S. Attachment in schizophrenia-implications for research, prevention, and treatment. Schizophr Bull. 2014;40(6):1189-93.

57. Mikulincer M, Shaver PR. Boosting attachment security to promote mental health, prosocial values, and inter-group tolerance. Psychol Inq. 2007;18(3):139-56.

58. Belsky J. Developmental origins of attachment styles. Attach Hum Dev. 2002;4(2):166-70.

59. Gotlib IH, Mount JH, Cordy NI, Whiffen VE. Depression and perceptions of early parenting: a longitudinal investigation. Br J Psychiatry: J Mental Sci. 1988;152:24-7.

60. Lado-Codesido M, Mendez Perez C, Mateos R, Olivares JM, Garcia Caballero A. Improving emotion recognition in schizophrenia with "VOICES": an on-line prosodic self-training. PLoS ONE. 2019;14(1):e0210816.

61. Branco LD, Cotrena C, Ponsoni A, Salvador-Silva R, Vasconcellos SJL, Fonseca RP. Identification and perceived intensity of facial expressions of emotion in bipolar disorder and major depression. Arch Clin Neuropsychol. 2018:33(4):491-501.

62. Dan O, Raz S. Adult attachment and emotional processing biases: an event-related potentials (ERPs) study. Biol Psychol. 2012;91(2):212-20.

63. Won S, Lee WK, Kim SW, Kim JJ, Lee BJ, Yu JC, Lee KY, Lee SH, Kim SH, Kang $\mathrm{SH}$, et al. Distinct differences in emotional recognition according to severity of psychotic symptoms in early-stage schizophrenia. Front Psych. 2019:10:564.

64. Ruocco AC, Reilly JL, Rubin LH, Daros AR, Gershon ES, Tamminga CA, Pearlson GD, Hill SK, Keshavan MS, Gur RC, et al. Emotion recognition deficits in schizophrenia-spectrum disorders and psychotic bipolar disorder: findings from the Bipolar-Schizophrenia Network on Intermediate Phenotypes (B-SNIP) study. Schizophr Res. 2014;158(1-3):105-12.

65. Boldrini T, Pontillo M, Tanzilli A, Giovanardi G, Di Cicilia G, Salcuni S, Vicari $\mathrm{S}$, Lingiardi $\mathrm{V}$. An attachment perspective on the risk for psychosis: Clinical correlates and the predictive value of attachment patterns and mentalization. Schizophr Res. 2020;222:209-17.

66. Quijada Y, Tizon JL, Artigue J, Kwapil TR, Barrantes-Vidal N. Attachment style predicts 6-month improvement in psychoticism in persons with at-risk mental states for psychosis. Early Interv Psychiatry. 2012;6(4):442-9.

67. DeTore N.R. MKT, McGurk S.R.: What does the Managing Emotions branch of the MSCEIT add to the MATRICS consensus cognitive battery? Schizophrenia Research 2020, in press.

68. Schnack HG, Kahn RS. Detecting neuroimaging biomarkers for psychiatric disorders: sample size matters. Front Psych. 2016;7:50.

69. Sanfelici R, Dwyer DB, Antonucci LA, Koutsouleris N. Individualized diagnostic and prognostic models for patients with psychosis risk syndromes: a meta-analytic view on the state of the art. Biol Psychiatry. 2020;88(4):349-60.

70. Antonucci LA, Pergola G, Passiatore R, Taurisano P, Quarto T, Dispoto E, Rampino A, Bertolino A, Cassibba R, Blasi G. The interaction between OXTR rs2268493 and perceived maternal care is associated with amygdala-dorsolateral prefrontal effective connectivity during explicit emotion processing. Eur Arch Psychiatry Clin Neurosci. 2020;270(5):553-65.

71. Wilhelm K, Niven H, Parker G, Hadzi-Pavlovic D. The stability of the Parental Bonding Instrument over a 20-year period. Psychol Med. 2005;35(3):387-93.

\section{Publisher's Note}

Springer Nature remains neutral with regard to jurisdictional claims in published maps and institutional affiliations. 